\title{
Guest-Editorial Introduction: Converging Evolutionary Patterns in Life and Culture
}

\author{
Nathalie Gontier ${ }^{1}$ (B)
}

Received: 25 July 2016/Accepted: 20 September 2016/Published online: 14 October 2016

(C) Springer Science+Business Media New York 2016

\begin{abstract}
The natural world demonstrates signs of spatialtemporal order, an order that appears to us through a series of recognizable, recurring and consecutive patterns, i.e. regularities in forms, functions, behaviors, events and processes. These patterns lend insight into the modes and tempos of evolution and thus into the units, levels, and mechanisms that underlie the evolutionary hierarchy. Contributors to this special issue analyze converging patterns in the biological and sociocultural realm across and beyond classic divisions between micro- and macro-evolution; horizontal/reticulate and vertical evolution; phylogeny, ontogeny and ecology; synchronic and diachronic sociocultural and linguistic research; and tree and network diagrams. Explanations are sought in complexity theory, major transitions of evolution, and process and mechanism approaches to change; and consequences for notions such as "life", "species", "biological individuality", "units" and "levels" of evolution are given.
\end{abstract}

Keywords Evolutionary patterns $\cdot$ Horizontal transmission - Vertical transmission - Microevolution . Macroevolution · Hierarchy theory $\cdot$ Systems theory · Diachronic versus synchronic research · Mode and tempo of evolution

Nathalie Gontier

nlgontier@fc.ul.pt

1 Centre for Philosophy of Science, Applied Evolutionary Epistemology Lab, Department of History and Philosophy of Science, Faculty of Science, University of Lisbon, Lisbon, Portugal

\section{Introduction}

In an anthology on Interpreting the hierarchy in nature, Rieppel and Grande (1994: 227) stated that "[s]ome of the most fundamental issues that scientists and philosophers face in evolutionary studies today concerns the relation of systematic patterns observed in nature to evolutionary process theories proposed to explain them...". Today, some 20 years later, the problem remains as fundamental as ever and has expanded from the biological to the sociocultural sciences that now also incorporate an evolutionary outlook to explain the change sociocultural phenomena go through in time and space.

The study of evolution often involves a choice between examining the various trajectories taken by natural kinds in history and providing a hierarchical, systematic and/or chronological sequence of events; or examining the causal processes that underlie the observed changes through time by listing the various mechanisms that induce evolution (Levinton and Futuyma 1982; Eldredge 1985; Rieppel and Grande 1994; Nuño de la Rosa and Etxeberria 2012; Gontier 2015b). The former involves a descriptive and pattern-based approach to evolutionary change, and the trajectories of natural kinds either become depicted in historical timelines or phylogenetic tree diagrams (Mayr 1942; Eldredge and Cracraft 1980) that, due to the large scale of analysis, involves macro-evolutionary sciences. The latter involves a process-based, often mechanistic way to explain change, and here, micro-evolutionary fields have favored natural selection acting on organisms and genes as the explanatory mechanism (Mayr 1961; Williams 1966; Dawkins 1976).

In linguistic (de Saussure 1916) and sociocultural (Malinowski 1922; Durkheim 1922) sciences, the pattern versus process/mechanism distinction is known as the 
diachronic/historical and synchronic/structural-functional approach. Scholars active in diachronic research examine the history of changes natural kinds have undergone in time and space which therefore also involves a macrolevel analysis. Synchronic scholars focus on a particular moment in time, often the present, and try and find the causes for the current functions of a sociocultural or linguistic system, which consequently involves a microlevel analysis (Gontier 2012, 2015b).

The methodological distinction is not absolute, either in the biological or the sociocultural sciences. In biology, both approaches were combined by Mayr (1961), in his paper on Cause and effect in biology. He distinguished between physiological and developmental biologists who seek the proximate causes of traits (how we walk or breath), and evolutionary biologists who ask about the functions (why we walk or breath). The former involves a structural-functionalist investigation into the present, i.e. ontogeny; the latter involves historical and evolutionary research, phylogeny. Mayr explained that proximate causes can only be made sense of in light of ultimate ones (Dobzhansky 1973), and thus that understanding ontogeny in the present implies knowledge of evolutionary processes that occurred in the past. This distinction between proximate and ultimate causes was later introduced into behavioral studies by Tinbergen (1963) and adopted by the sociocultural evolutionary sciences.

This special issue focusses on evolutionary patterns, but following Mayr and Tinbergen, in no way excludes process theories that try and explain the patterns. Pattern and process are often intrinsically related, and any and all theorizing on evolutionary patterns furthermore involves an identification of the units and levels of analysis, which happens either in nature or in a theoretical hierarchy.

The relation between pattern and process has become more obvious in recent years in biology due to macroevolutionary research on the mode and tempo of Darwinian evolution (Eldredge and Gould 1972; Eldredge and Cracraft 1980), as well as systematic gene-based analyses (Woese 2004) that prove beyond reasonable doubt that besides vertical patterns of descent that can be explained by natural selection theory, life's history is characterized by reticulations or network-like patterns. Both gradual and punctuated equilibria patterns can be explained by natural selection theory, but especially the study of the former has in addition to the pattern of gradual descent with modification brought forth research on patterns of morphological stasis and developmental constraints. Reticulate patterns are explained by processes and mechanisms that underlie lateral gene transfer, symbiogenesis, and hybridization (for an overview, see Gontier 2015a) and these raise questions not only on the tempos but also on the various modes of evolution.
While gradual descent with modification can indeed typify aspects of sociocultural and linguistic change through time and space, reticulations also characterize diffusion studies on the world's languages and cultures (Kroeber 1923; Croft 2000, 2002). The network-like patterns that typify cultural and linguistic information exchange used to make anthropologists and linguists refrain from evolutionary research, but today, the wide recognition of reticulate evolution in the biological sciences, together with the implementation of evolutionary theory into the sociocultural sciences, is bringing forth new means to model the often rapid horizontal transmission of sociocultural and linguistic traits (Croft 2000, 2002; Atkinson 2010; Nelson-Sathi et al. 2013, 2014).

Tree and network diagrams also no longer confine themselves to the historical, systematic or diachronic study of natural kinds. In fact, many evolutionary diagrams today remain historically unrooted, and depict phenomena within both the biological and sociocultural realms that occur in what might be called the "living or continuous present (Lebendige Gegenwart)", a term borrowed from Husserl (1928), or what both biologists and sociocultural scientists designate as the "economy" or "ecology" of nature, which follows Haeckel (1866) who defined it as the "conditions of existence". Evo-devo schools have taught us that these conditions of existence are partly determined by the "inner environment" (Gould and Lewontin 1979) or ontological and developmental processes; while evo-eco schools focus on how the "outer environment," made up of other individuals (Van Valen 1976) and abiotic phenomena (Vrba 1985), determines the economy of nature.

Besides lending insights into phylogeny, ontogeny (that encompasses morphological form and functional behavior), and ecology, recurring patterns often provide the first entry points to examine how information is exchanged, and they help to identify the units of evolution, the levels where they evolve, and the mechanisms and processes that underlie their change (Gontier 2011). As such and beyond evolutionary diagrams that track (aspects of) natural kinds in time and space, recurring patterns underlie theoretical generalizations.

\section{Defining Patterns and Their Functionality for Evolutionary Research}

Patterns are regularities in forms, functions, behaviors, events, and processes that recur in time and space. They lend insight into the modes and tempos of evolution and thus into the units, levels, and mechanisms that underlie the evolutionary hierarchy and its major transitions. Patterns can be deduced from observed data, simulations and 
models of the natural world, and in all cases, they require an observer.

Much of science and philosophy is characterized by examining how well the phenomenological world we live in, i.e. the biological reality we perceive through our observations and cognition, match with the world as it is in itself (Gontier and Bradie, forthcoming). Our observations are partly determined by our evolved physical and neurocognitive constitution that is particularly well-suited to deal with a world of middle-sized objects (Vollmer 1984); and partly by the scientific instruments we have developed over the years that enables us to observe and analyze the micro- and macroworld. Scientific simulations and models express our accumulated data and knowledge and depend upon theoretical premises defined by scientific paradigms (Kuhn 1962) that in turn find their roots in sociocultural intuitions (Pinxten 1997). Patterns are therefore often theoretical constructs that on an epistemological level enable us to conduct scientific research and the delineation of patterns encompasses a cultural scientific practice.

How "real" patterns are, i.e. how and if a pattern converges with the actual, ontological state of the universe, is something we cannot fully determine which is why all scientific research is bounded by the epistemic framework one works in. Nonetheless, there are a couple of criteria that we can list to which patterns need to adhere before they qualify as objects of scientific research and practice. In all cases, the observed regularity requires repetition. And like any object of study, patterns also need to meet requirements of independent confirmation and a failure to falsify the observed regularity by members of the scientific community.

Pievani opens the issue and further explains how recurring patterns in natural history function as heuristic tools of scientific discovery that enable us to build the scientific program. Following Eldredge (1999), he defines evolutionary patterns narrowly as "regularities and recurrent schemes in the transformational processes of organisms and species" and generally as "scheme[s] of repeated historical processes and events". Such regularities demonstrate that evolution is not a random process.

The most straightforward recurring pattern found in the transformational process of species is what Darwin (1859) called "descent with modification". He explained this pattern by natural selection theory that in turn builds upon observed patterns of variation, inheritance and fitness of individual organisms (called the Darwinian principles by Lewontin 1970), in conjugation with ideas on competition and a struggle for existence in the economy of nature. Taken together, these factors underlie shifts in populations over time which brings forth new species. Darwin postulated such speciation to occur gradually, which today is confirmed by patterns of phyletic gradualism. In addition, data demonstrates that speciations often follow a pattern of punctuated equilibria (Eldredge and Gould 1972), where long periods of morphological species stability or stasis are intermitted by short periods of rapid change. Because both patterns find scientific support, Pievani avers for a more pluralistic understanding of the means whereby speciation occurs.

Beyond pluralistic views on speciation, the author details how scholars have discovered multiple and varied sources and patterns of variation, not only at a genetic but also at an epigenetic level which has engendered notions of inclusive inheritance. Scholars active in evo-devo schools have observed patterns of developmental constraints and information channeling, and ideas on niche construction and kin or group selection alter how we define environmental selection and competition. These discoveries have often gone hand in hand with polemic debates on the adequacy of the Modern Synthesis and whether or not we need to extend it. Pievani takes the Laland et al. (2014) article as point of departure to argue that though the plurality of patterns do not falsify the Neo-Darwinian framework, they nonetheless require integration into a new metatheory of evolution. Pievani suggests that Eldredge' hierarchy theory, that distinguishes between a genealogical and ecological hierarchy, could serve as the basis of that larger framework. The genealogical hierarchy integrates the Darwinian principles of differential variation, inheritance and fitness, while the ecological hierarchy encompasses the different levels of environmental selection along with more general processes of matter-energy exchange that take place within the economy of nature.

\section{Trees, Networks and the Patterns of Transmission, Affinity, Diffusion and Dispersal}

A large part of evolutionary research is concerned with defining the units of evolution and consequently with defining information, examining its transmission and exchange. Population and molecular biologists define the unit of information as the gene, and comparative genetic research enables scholars to draw genealogical pedigrees and phylogenetic trees that depict evolutionary relatedness amongst species. Tree models demonstrate a vertical pattern of common descent with modification amongst the various species and also lend insight into speciation processes and biodiversity.

The sociocultural and linguistic sciences, and also ecological, reticulate and biomedical evolutionary sciences often define the unit of evolution more broadly in order to include the horizontal and reticulate exchange of information that typifies language borrowing or culture contact, the differential exchange of matter and energy that takes 
place in the economy of nature, and the transmission and acquisition of foreign and extra-nuclear DNA, organelles, or microorganisms that influence health and disease. Beyond genealogical and therefore vertical modes of transmission, these scholars examine:

1. Horizontal transmission of information (possibly followed by vertical descent) between contemporary organisms often belonging to distinct species-examples in the biological sciences include hybridization and lateral gene transfer (which are both gene-based), symbiosis and symbiogenesis (organism-based); and in the behavioral, sociocultural and linguistic sciences examples include the intraspecific diffusion of behavioral, linguistic and cultural traits (not all of which are matter-based), which due to incoming evidence of hybridization events within the hominin lineage (Curnoe et al. 2015; Green et al. 2010; Prüfer et al. 2014; Vernot and Akey 2014) now have to be taken to an interspecific level of analysis;

2. Oblique or indirect vertical transmission traditionally defined by Cavalli-Sforza and Feldman (1981) in the sociocultural sciences as information exchange going from one or more non-kin members of an older generation to individuals belonging to a younger generation-examples include unguided observational learning as it occurs in our and other primate species or master-apprentice relations;

3. Directed transmission, also defined in the sociocultural sciences, by Campbell (1965) and Boyd and Richerson (1985), as guided variation and information exchange-teaching, for example (the difference with oblique transmission lies in the latter's emphasis on information exchange from an older to a younger generation, while directed transmission puts emphasis on the variation bias that intentional teaching brings forth); and also biologists debate whether or not genetic mutations (Cairns et al. 1988), lateral gene transfers (Popa et al. 2011), eco-evo-devo phenomena such as phenotypic plasticity (West-Eberhard 2003) and niche construction (Gould and Lewontin 1979), or physical, biochemical and developmental constraints and affordances (Turing 1952; Gould 1977, 1986; Pearson et al. 2005) are random, contingent or directed; and

4. Reversed transmission, where in the sociocultural domain younger generations transmit information to older generations - think of a grandchild teaching his grandparents how to use a cell phone (Gontier 2006b); and in the biological domain, especially during epigenetic changes the flow of information becomes reversed, going from proteins to RNA to DNA (Jacob and Monod 1961). This illustrates instances of downward causation (Campbell 1974b) where, when looked at from a hierarchical perspective, upper or later evolved levels influence the evolution of older or lower levels (cultural practices change biological evolution, for example).

When these interactions and informational transmission modes are modelled, they result in network diagrams that display reticulation patterns. Beyond the study of interactions and information exchange, network diagrams are inherent to biogeographic and sociocultural ecological research where scholars examine the non-genetic distribution/dispersal/migration/diffusion and occupancy/density/diversity of natural kinds. Network diagrams also emerge from non-genetic comparative research where scholars map morphological and other affinities.

Morrison contributes a historical overview on the origin of tree and network analysis in both the biological and linguistic sciences, and he outlines the various methodologies used to depict genealogical relations and more general affinities. The differential use of tree and network iconography, for the author, lends insight into just how complex the scientific community perceives relationships that exist between natural kinds to be. Both trees and networks are part of graph theory, where nodes (break points or intersections) become connected by edges (lines). Genealogical trees are directed acyclic graphs and therefore illustrate (multi-)linearity in time. Networks are more complex because they allow reticulations between nodes.

Today pedigrees display the genealogical relationship amongst individuals on a micro-scale, a relationship that is understood in genetic terms, while phylogenies portray the genealogical relationship there exists amongst groups of individuals on a macro-scale. Pedigrees and phylogenies are often pictured as trees where diverging branches lend insight into vertical descent lines, but the author notes, these trees are often simplified networks, especially when they portray the genealogy of sexually reproducing species. Reticulations represent affinities or interactions and contact that occurs between species, languages and cultures. Networks furthermore enable depictions of the dispersal and diffusion of languages and the biodiversity and biogeography of life. Affinity or interaction diagrams often remain historically unrooted, and Morrison notes that during sociocultural situations, no vertical time-consistency is required because the directionality of information flow can change. Scholars are nonetheless developing several ways to infer historical relationships in these networks, but at present no unifying mathematical technique exists.

Morrison goes on to analyze how patterns produced by diagrams relate to the processes and mechanisms of evolution. Natural history knows three types of processes: 
divergence, convergence and parallelism, and all are explained by a variety of mechanisms. Processes of divergence are brought about by mechanisms of natural selection; convergence results from mechanisms underlying recombination, re-assortment, hybridization, introgression, lateral gene transfer, and symbiogenesis. Parallel evolution occurs when unrelated species evolve similar to one another, either due to chance similarity or due to similar selection pressures. Divergence will lead to tree diagrams while divergence with convergence leads to networks, and parallel evolution obscures clear tracking of information flow. The author cautions that patterns emerging from mathematical analyses merely procure hypotheses on natural history, and because they are often similar in appearance, they disable a straightforward linkage to causal mechanisms of change.

Like Morrison, Kressing examines how before the introduction of natural selection theory, historical linguists of the nineteenth century mapped the origin and dispersal of several of the world's largest language families, the diffusion of their vocabulary and the development of their grammatical features, by making use of network diagrams. Network diagrams that demonstrate affinity were also common in biological schools and Kressing in particular highlights how, on a meta-level, this induced an intense cross-fertilization between linguists and biologists in what regards the exchange of tools and modelling techniques for tracing the history of natural kinds. The adoption of natural selection theory resulted in a steady decline in the use of network diagrams in favor of vertical diagrams in both the biological and sociocultural sciences.

Attempts to model sociocultural and linguistic evolution in tree models gave way to historicist theories that bestow unilineal explanations of sociocultural change. Often associated with stage thinking, some languages and cultures became defined as "under-" developed or "primitive" in comparison to Western cultures. These often racist and evolutionist instead of evolutionary theories were questioned at the turn of the twentieth century, by schools of Social Anthropology in Britain, Ethnologie in France, Völkerkunde in Germany, and Cultural Anthropology in North America. All fiercely combatted the unilineal assumptions made on cultural evolution and often ended up rejecting evolutionary theories of sociocultural change altogether, in favor of notions such as historical particularism or diffusionism that continued to examine horizontal information exchange. The horizontal diffusion of linguistic traits became studied by areal typologies of languages. Because diffusions involve phenomena such as language borrowing and culture contact, the fields of anthropology and linguistics developed independently from the overall biological sciences, often by developing new techniques to map reticulations.
Eventually evolutionary thinking became reintroduced into sociocultural research in the first half of the twentieth century, and today, both tree and network diagrams are used to understand the historical and evolutionary change languages and cultures go through in time. Kressing explains how this reintroduction is again due to an intense interdisciplinary cross-fertilization, where techniques used to model hybridization and the horizontal transfer of genetic material are implemented to study sociocultural and linguistic change.

Mesoudi and de Voogt elucidate on some of the similarities and particularities that exist between biological and cultural evolution. When Neo-Darwinians study the evolution of species, they investigate genetically transmitted information, while sociocultural scientists such as Mesoudi define cultural evolution as "socially transmitted information, including beliefs, knowledge, skills and practices". Though genetic information is quite different from cultural information, both types of information create variation, and both can be transmitted, if not by genes then by social learning practices. Variation, together with differential inheritance (or transmission) and fitness (or selection), are the three Darwinian principles according to which natural selection operates, and Mesoudi explains how these principles can characterize cultural evolution on a micro- and macroscale. He reviews from a methodological point of view how scholars have applied concepts, tools and techniques developed in the biological sciences to explain cultural change within and amongst populations.

Such research has elicited large-scale patterns and trends in sociocultural evolution, of which Mesoudi highlights some of the most intriguing ones. For one, social learning is payoff biased and conformist. Decisions taken at an individual level to follow the majority, because it is more rewarding for the individual, generate patterns of group conformity at a population level, which facilitates group formation and cohesion. Secondly, cognitive biases drive cultural evolution toward cultural attractors (Claidière and Sperber 2007). Cultural information (or variation) is often directionally altered by the individual, who modifies the information in such a way that it becomes cognitively accessible to that individual, which biases not only the information but also guides the trajectory it takes. Transmission chain studies on storytelling conducted by the author, for example, demonstrate that during iterated transmissions of the same story amongst different individuals, details get lost and the story becomes more generic over time (which is comparable to McShea's machinification trend, discussed later in the text). Human cognition thus actively shapes cultural evolution by providing directional constraints on the types of information that can become passed on. Thirdly, and from an ecological point of view, group size, population density and migration can 
influence the evolution of cultural complexity. Smaller groups have less cultural variation in skills and practices while larger groups have more variation because there are more individuals to learn form. Isolated groups often lose complex skills over time. Fourthly, phylogenetic methods used to reconstruct the dispersal of language families demonstrate that in addition to gradual patterns of change, language families also undergo "pulses" and "pauses" (Gray and Jordan 2000), a pattern that is comparable to the punctuated equilibria found in the fossil record; and scholars are more and more able to map the reticulations intrinsic to sociocultural change.

For Mesoudi, cultural macro-evolution finds its causality in micro-evolutionary processes because the large-scale patterns or trends can be explained by referring to dynamics occurring at the micro- and mesoscale. The benefit of cultural macro-evolutionary studies is that it enables scholars to compare cultures, which was considered impossible by the historical particularists reviewed by Kressing. Contrary to sociobiological schools of thought and evolutionary psychologists, who investigate the proximate causes of cultural behavior by tracing culture back to genes and investigating inclusive genetic fitness, the author argues that cultural evolution can play an ultimate causal role, by driving behavior to novel equilibria and by introducing a second inheritance system based upon social learning strategies.

De Voogt exemplifies the peculiar nature of cultural traits with writing systems and board games. Both are material artifacts invented by humans and both have a physical, material appearance and a set of culturally-defined rules on which letters to write or how to play the game. Changes in either the rules or the physical appearance can be decoupled from one another and these changes enable a variety of qualitative field work and quantitative data analysis (modelling), including diachronic (historical), genealogical (via their human inventors), biogeographic and ecological research.

The author reviews how writing systems have been borrowed and modified from neighboring languages, even when they form part of different language families, and they have been transmitted vertically, horizontally and obliquely. Board games cross linguistic and cultural boundaries, and have a wide geographical dispersal. Each variation appears to undergo its own peculiar modes of transmission. The rules or information on how to write or manufacture board games are transmitted via language, but language does not always appear to pose a cultural boundary during the transmission process.

Cultural transmission of information is much less rigid than genetic transmission, and these aspects warn against macro-evolutionary studies that, because of the scale involved, often homogenize the material cultural traits they track in time and space. This continues to result in divided epistemological stances between classic archaeological and anthropological fields that favor ethnographic descriptions or adopt cultural diffusion theory, and historical and comparative linguists and archeologists that adopt Darwinian cultural evolution models. de Voogt points out how both fields can benefit from each other's datasets and modelling techniques, and he gives some useful directions for future research.

\section{Transitioning from the Cosmic to the Biological to the Psycho-Social}

Ever since Plato (Harte 2002), we have been fascinated with how wholes decompose into parts and how parts connect to one another to form larger wholes thereby giving structural order to the universe along with identity and individuality to its compositions. The ancient Greeks distinguished between different cosmic scales, the micromeso- and macrocosmos, which formed an embedded hierarchy that later became redefined as the inorganic, organic and super-organic by Hutton (1788) in the geo- and biological sciences and Spencer (1876) in the sociocultural sciences. The inorganic, organic and super-organic division still reflects the way in which we organize academic disciplines today (Smocovitis 1996), from particle physics and chemistry over the evolutionary sciences to the earth and planetary sciences.

Neither of these distinctions however correspond with the current standard models on the origin of the universe and the evolution of life (Gontier 2015b), which is why Huxley (1942, 1957) redefined the hierarchy in a diachronically more realistic line up as going from the cosmic to the biological to the psychosocial. These hierarchies correspond with the three most puzzling problems science wants to solve: the origin of the universe, the origin of life, and the origin of neurocognitive and sociocultural behavior. For all three problems, scholars have long assumed breakpoints: there was no universe and a moment in time and space, as Newton would say, when it came into existence, a period where there only existed inorganic material and a period where living organisms emerge, and a period where life was only defined by its genetic and biochemical constitution and a period where that life transcends its material constitution to display behavior, including of a cognitive and sociocultural kind.

Today the assumed boundaries and break points have cleared room for qualitative and quantitative transition thinking and the changes are redefined either in evolutionary terms or in terms of rises in complexity, or both. Many physicists suspect that the big bang does not mark the beginning of the (single) cosmos (Borde et al. 2003); 
accumulating evidence points toward multiple origins of life which in turn questions the idea that all species share common descent (Woese 2004; Margulis and Sagan 2000); and even sociobiology is nowadays applied to understand the differential behavior portrayed by prokaryotic beings (Dunny et al. 2008; Nadell et al. 2009). The fuzzy boundaries between the inorganic, organic and superorganic, or the cosmic, biological and psychosocial have repercussions for how we define life and culture. While the origin of the universe is a question for physicists, in this volume Kolb examines the origin of life out of non-living matter, and Bradie and Bouzat investigate the evolution of cultural beings from biological individuals.

Turning to the origin of life, the standard view defines life upon its structural composition as that what is made up of genes, proteins and a cell, and it understands the single cell as the most basic unit of life (Margulis and Sagan 2000; Schrödinger 1942). These structural elements are all built up from inorganic matter, no structural "life element" can be found. Nucleotides together with phosphates and sugar build genes, amino acids build proteins, and the cell membrane is built up from proteins and lipids. Such implies that the origin of life involves a transition from the inorganic to the organic, and causality for that transition is sought in the inorganic realm, because what did not yet exist cannot be counted responsible for what came into being.

In a modern cell, genes encode for proteins, including proteins and lipids that build its membrane but disputes arise on how life originated and which came first, the building blocks of proteins (Kauffman 1971, 2011), genes (Orgel 1973; Eigen 1971) or cells (Oparin 1968; Oparin and Gladilin 1980; Fox and Dose 1977). Morphological definitions are accompanied with functional definitions and with how we causally define life's evolution, in terms of the evolutionary mechanisms involved. Functionally, life is defined by its ability to metabolize and (self-)maintain as well as its ability to replicate information and (self-)reproduce. Many biochemical entities can self-assemble and self-maintain without the presence of natural selection. Rather, they arise through what used to be called "spontaneous generation" or a "natural attraction" that exists between molecules, which we today can causally explain by referring to physical and biochemical laws and mechanisms. Self-replication is gene-based and therefore associates with the origin of genes as information systems and the introduction of the three Darwinian principles (differential variation, reproduction and fitness/selection) acting on these information systems.

The origin of self-replicating genes is hypothesized to have occurred in an RNA world. For Maynard Smith and Szathmáry (1995), for example, and following scholars such as Eigen (1971), the transition from non-living matter to life associates with the passing of the Darwinian threshold (Woese 1967), i.e. when the Darwinian principles become reached. Evidence for the RNA world hypothesis (Woese 1967; Gilbert 1986) is found in ribozymes, RNA molecules that can function both as genes and enzymes (Cech et al. 1982; Guerrier-Takada et al. 1983). Before the current transcription and translation machinery was introduced where DNA (information) encodes for proteins (metabolism) via RNA, RNA could have both stored its information and acted as its own catalyst by performing the catabolic and anabolic functions required to replicate itself. The division of labor that subsequently arose between DNA, RNA and proteins involves a rise in complexity and is hypothesized to have occurred later in time.

While it is highly likely that ribozymes precede the origin of the genetic code and its complex translation machinery, we also have clear evidence, through the Miller-Urey experiments (Miller 1953), that amino acids could have formed in the early atmosphere independently of genes that encode for them. In fact, over 500 amino acids have been described so far, and only 20 are encoded for by genes and put to use in the formation of living entities. Amino acids can "spontaneously" (within the limits of chemical and physical laws) form bonds and catalyze into larger molecules such as polymers where single units become repeated into larger chains, thereby introducing a form of molecular reproduction that is void of natural selection based upon replication (Kauffman 1971, 2011). The "naked" RNA world could have included such chemical inhabitants, or it could have been preceded by such an era of biochemical evolution.

The nucleotides that build genes are also found independently in the atmosphere and they are scattered through space (meteorites that fall on earth often contain them). But their presumed distance apart and the relative short "halflife" nucleotides seem to have, makes it less likely for these entities to have been in contact with one another outside a compartment such as a (proto-)cell. In general, "naked genes" are very vulnerable to breakdown by environmental causes and a (proto-)cellular structure would better protect the processes of compartmentalization of replicators into chromosomes, or the establishment of a translation machinery. A cell would also bring the various components closer together, thereby increasing the possibility to interact.

Kolb describes experimental research on such protocells that could have preceded or facilitated the RNA world. Coacervates are biochemical cell-like structures that can be synthesized under lab conditions that simulate the primitive earth (Oparin's 1968, 1969, 1980; Fox and Dose 1977). Coacervates are able to encapsulate and absorb chemical matter, they can facilitate catalytic reactions inside their structure, and they can split into daughter cells and thus 
undergo rudimentary forms of reproduction, all in the absence of genetic material. Oparin's coacervates were made up of gelatin (polypeptides) and arabic gum (polysaccharides), but only the latter can be artificially composed from prebiotic elements. Kolb therefore experimented with a structure that is able to self-construct from the elements present in prebiotic chemistry. Her AOTmolecule (Dioctyl sodium sulfosuccinate) can form coacervates that are able to function as chemical reactors.

In the second part of her paper, Kolb investigates various definitions of life, including definitions that explain living organisms as entities that are able to self-maintain and reproduce through replicating genes, and tests them against curiosities such as viruses. Viruses are entities that can selfmaintain but not self-replicate, for the latter they require the metabolism of living organisms. Kolb redefines life as a qualitative change in the complexity of organic chemical systems that is characterized by the ability of temporal selfmaintenance and self-preservation. This temporal dimension enables her to include viruses that integrate into a host (during the lysogenic stage) amongst the living. The status of viruses as transitioning entities between the living and the dead is also reviewed by Casiraghi et al., discussed later.

The transition from the organic to the superorganic in turn has been redefined in terms of gene-culture co-evolutionary theories (Boyd and Richerson 1985) that yield ideas on "dual inheritance". The rationale behind these movements is that biological organisms are able to display cultural behavior partly because of their biological constitution (they evolved culture), but once cultures exist, these cultural systems themselves evolve, often in ways different from biological evolution. As Mesoudi noted, culture can demonstrate forms of "directed selection", and not all cultural behavior can be causally explained by genes. For that reason, he defines cultural evolution as "socially transmitted information, including beliefs, knowledge, skills and practices", and he emphasizes that this information evolves according to Darwinian but not neo-Darwinian, genetic selection.

Dual inheritance theories find their origin in ethological (Lorenz 1941, 1958, 1977, 1985; Tinbergen 1963), behaviorist (Skinner 1953, 1984), comparative psychological (Piaget 1950) and evolutionary epistemological (Campbell 1959, 1960, 1997; Bradie 1986; Munz 1993) schools of thought. These schools commenced the scientific study of behavior and the cognition required to display it, and both cognition and behavior became understood as evolved traits that from an evolutionary epistemological perspective enables organisms to embody, acquire and conceptualize knowledge (for overviews see Gontier 2006a, b; Gontier and Bradie, forthcoming). Lorenz, for example, aimed to develop a taxonomy of behavior and cognition that could map onto genealogical phylogenies,
Piaget distinguished various stages of human cognition, and Campbell attempted to identify the phases and hierarchical transitions in knowledge acquisition from bacteria onward.

These scholars define knowledge broadly as not merely encompassing scientific thought and practice, language or culture, it includes anatomical traits, senses and perceptions, mobility, instincts, and cellular processes. Today we know that even genes can produce different traits depending upon their location and time of activation within the genome, and such can be considered differential behavior that manifests a form of evolved knowledge. This implies that the acquisition of knowledge need not require cognition, consciousness or intentionality. Any and all biologically evolved traits are understood as inductively acquired types of knowledge on how to act within the internal (bodily) and external environment (Lorenz 1941; Campbell 1974a). Processes such as mimicry illustrate how, through natural selection or "blind variation and selective retention," adaptive anatomical and behavioral traits have evolved that enable species to survive and reproduce differentially, and such traits literally embody evolved knowledge on the environment and how to act in it. For Campbell (1965), and before Lewontin (1970), "blind variation and selective retention" characterized the (Darwinian) principles that are recursively repeated at all levels of knowledge acquisition. By applying natural selection theory not only to the evolution of anatomical form but also to behavior and cognition, these scholars undid the ontogeny-phylogeny divide and loosened the boundaries between form and function (structural anatomy versus behavior or cognition).

Culture, which is one type of knowledge, can be found in numerous species, and here too drawing the boundaries between biological or social and cultural behavior becomes a matter of definition. Bradie and Bouzat investigate how cultural beings evolved from biological beings, and how the decoupling between the cultural and biological realm can come about. They distinguish three separate phases that follow one another: non-cultural species gave way to protocultural species which gave way to fully cultural species.

Crucial to understanding the transitions from one phase to the next for the authors is the notion of reaction norms (Schlichting and Pigliucci 1998). Reaction norms refer to the amount of plasticity genotypes have, via their phenotypes, to react differentially toward various environmental conditions. Non-cultural organisms possess genotypes with little to no plasticity (their reaction norms are fully determined by their genes or by fixed action patterns that are triggered by environmental responses), while cultural phenotypes show a high level of independence of their genotype (because through learning, they possess a wide variety of behavioral responses). 
The scholars explain how the early stages in cultural evolution can be causally explained by Darwinian processes acting on geno-and phenotypes, while the later stages of cultural evolution cannot because cultural traits are displayed autonomously from the genome and the transmission modes and mechanisms whereby cultural traits evolve are different from genetic selection. For that reason, the biological capacity to evolve culture has to be decoupled from the modes by which cultural traits change, which gives way to the dual inheritance system that is characterized by a dual causality. Methodologically speaking, this distinction correlates with the division between two research programs in evolutionary epistemology introduced earlier by Bradie (1986): the EEM or evolution of enabling mechanisms program, and the EET program that investigates the products or outcomes of cultural change.

\section{Complexity, Hierarchies, Transitions and Trends}

Evolutionary biology has mostly been defined at a mesolevel of analysis. With on the one hand the rise of molecular genetics and biochemistry (Kay 1996), and on the other the introduction of macro-evolutionary theory in biology (Simpson 1944; Eldredge and Gould 1972) as well as the inclusion of sociocultural and linguistic fields into the evolutionary sciences (for an overview, see Gontier 2012), the micro- and macro or in- and super-organic have steadily been incorporated into the evolutionary paradigm. This has resulted in evo-devo or evolutionary developmental schools (Jacob and Monod 1961; Gould 1977; Gehring 1992; Jablonka and Lamb 1995; Hall 1999; Carroll et al. 2005; Love 2003; Müller 2007; Gilbert and Epel 2008) where scholars investigate how biochemical processes and gene-regulatory networks or behavioral patterns underlie the evolution of organisms and the societies they form; and evo-eco or evolutionary ecological schools (Allen and Starr 1982; Eldredge 1985; Salthe 1985; O’Neil et al. 1986; Fox et al. 2001; Mayhew 2006) where scholars examine how the different species that make up the biotic world interact with one another and with the abiotic world. Evo-devo and evo-eco are currently synthesized into ecoevo-devo movements (Abouheif et al. 2014) that attempt to include all layers of reality into the evolutionary paradigm.

From their onset, evolutionary sciences have tried to scale the origin of the hierarchical layers in time (via the introduction of timelines), and they have attempted to assess the various scales based upon their level of complexity. This has brought forth structural hierarchical views on the very nature of (biological) order, organization or compositionality (Simon 1962, Koestler 1967, Pattee 1970, 1973); theorizing on the major transitions of evolution (Maynard Smith and Szathmáry 1995) where scholars investigate how lower-level parts combine and actually induce the formation of higher-level systems of biological organization; and investigations into the possibility of directional change where researchers try and identify arrow(s) of time (Blum 1951; Gould 1989) or (recurring) trends (McNamara 1990) in life's evolved lineages. With Morrison we know that the diagrams used to depict certain phenomena reflect the levels of complexity scholars attribute to those phenomena. This also holds for how we understand hierarchies, transitions and arrows or trends.

The tripartite hierarchies have become differentiated into many more levels, and beyond describing the history of natural kinds, scholars have sought the mechanical means whereby transitions and trends occur. This ushers reductionism versus holism debates that have divided scientists on the nature of the scientific enterprise. Should scholars focus on describing and reconstructing the past, or explain why things are as they are, by finding the causal mechanisms of change? This question is accompanied with queries on historical uniqueness (Gruner 1969), randomness (Wimsatt 1980), contingency (Gould 1989), and determinism (Ayala 1970, Conway Morris 2003) and thus with the lack or existence of recurring patterns, the (im)possibility to predict the future course of evolution, and the very nature and (un)directedness of change.

Quite some epistemological confusion resides between research programs that focus on hierarchies, transitions and arrows or tends in time, and most of it can be explained by looking into history. Hierarchical thinking is the oldest way in which scholars have theorized how parts compose to form larger wholes that are characterized by an increase in complexity. In the biological sciences, scholars originally focused on the structures (the patterns that underlie the composition) of morphological form, instead of researching the relations or interactional patterns that exist between the components that make up the structure. Scholars such as Haeckel (1866, 1917) and d'Arcy Thompson (1917) conceptualized the evolution of life in terms of compositional morphological structures that diachronically and therefore linearly progress through terminal addition. The chronological sequence wherein discrete patterns follow one after the other are interpreted as expressions of a static developmental staging for which they respectively proposed the "law of biogenesis" and physical and mathematical laws that explain geometric transformations (for a discussion see Nuño de la Rosa and Etxeberria 2012).

Equally, when DNA was first observed, it was thought to be a static structure, and theorizing on the nature of hereditary material originally supposed that one gene linked to one enzyme (Beadle and Tatum 1941). With the discovery of DNA (Avery et al. 1944) as the locus of 
hereditary information and the subsequent analysis of its molecular structure (Watson and Crick 1953), the genetic code became interpreted as a "frozen accident" (Crick 1968) and only later did the transcription and translation properties become identified which gave way to more dynamic views on how form comes about.

Structuralism and structural functionalism is also what characterizes the onset of the economic (Marx 1890), anthropological (Malinowski 1922, 1945), sociological (Durkheim 1922), and linguistic (de Saussure 1916) sciences, where underlying static structures determine the functions of the whole through the sum of its components in closed (synchronic) systems.

Today, hierarchy thinking (Eigen 1971; Kauffman 1971; Pattee 1973; Eldredge 1985; Salthe 1985; O'Neil et al. 1986) no longer follows this rigid and deterministic structuralism because scholars have long recognized that the parts not merely compose the whole (and thus that they do not function as automata), but that the whole "emerges" through the interactions between the parts. Systems, be they biological, social, linguistic or cultural in kind, are "partly open and partly closed," and leave room for nondeterminism. Partly influenced by and partly defining the jargon of systems theory, biophysics, information theory, cybernetics, and biosemiotics, it are hierarchy builders that have adopted concepts such as "division of labor"; "information", "complexity", "(self-)replication", "homeostasis" or "self-maintenance and self-organization", "control", "affordances and constraints" and "up- and downward causation" to describe the levels of biomolecular, biological or sociocultural organization, and their formation, in more dynamic terms. Beyond providing the jargon to describe these diverse phenomena, hierarchy builders have been incorporating physical, mathematical and economic/ecological laws to describe, calculate and measure the formation of the levels. In this respect, though numerous often historicist and unilineal attempts have been made to find laws of sociocultural change, the sociocultural sciences have failed to find any such laws and they have abandoned the quest altogether, which is why they favor descriptive research.

Szathmáry and Maynard Smith (1995) suggested that the increase in complexity found in natural history is due to major transitions that involve changes or reorganizations in the way information is stored and transmitted over time, but not, for example, how life biogeographically expands or self-maintains (Benton 2009). Today major transition thinking follows a life of its own, but the epistemic tradition does not differ that much from systems and hierarchy theory because they build on the same vocabulary and they follow the diachronic (and therefore historically linear) sequence presented by the original hierarchy thinkers, going from individual replicators to unicellular to multicellular life forms and the sociocultural groups they form. Instead of focusing on the entities that make up the hierarchy, and the relations and interactions that exist between them, they often focus more on how the transition in "qualitative change", "biological organization" or "complexity" comes about. While the original hierarchies served to describe the nature of the cosmos and later the evolutionary history of natural kinds in time, transition scholars try to give an explanation for biological organization and the transition from one level to another, by making use of natural selection theory which both implies a reductionist and a causally mechanistic stance. "Complexity" and "organization" become defined by Lewontin's "Darwinian principles", i.e. as having differential variation, inheritance and fitness (or selection), and these "functional properties" not merely define each level of organization, they are held mechanically responsible for bringing forth the next (hierarchical) level of biological organization. So the approach implies a "Darwinization" of the hierarchy, whereby selection theory provides the explanatory framework for why the hierarchies are what they are.

The linearity associated with old natural history stage thinking has from its onset rendered speculations on directionality in time, which in the sociocultural sciences associated with historicist and unilineal ideas on culture (for a history and critique see Boas 1940, Popper 1957, and Gould 1981), and in the biological sciences associated with orthogenetic views (for a history and critique see Simpson 1953, Futuyma 2015) that conjoined élan vital movements that sought the "driving forces" behind the directionality. Today, questions on directionality continue to be raised in especially biophysical sciences where the second law of thermodynamics is considered time's arrow (Eddington 1928; Prigogine 1980, 1990), and in the macro-evolutionary sciences (Gould 1988, 1989; McShea 1998, 2001) where scholars debate the existence of "trends" and "arrows in time" within existing lineages of a biological hierarchy. Besides natural selection, other mechanical explanations are put to use, and many trends can be explained as random side-effects or passive (McShea and Brandon 2010), having no apparent causal mechanisms for their persistence. Szathmáry and Maynard Smith (1995) furthermore pointed out themselves that the major transitions they distinguish all share the following basic patterns or trends: (1) independent entities join to form a larger whole where the individual parts become dependent upon the newly formed entity (and dependence becomes defined in terms of replication); (2) loss of independence and integration into a larger whole introduces task specification amongst the parts and thus associates with the division of labor; and (3) all transitions involve changes in how information is stored, transmitted and communicated. 
These recursive patterns can also be understood as sequentially linear, and thus as possible arrows in time.

Boundaries between these schools of thought are fuzzy because any hierarchical system or theorizing on major transitions produces a historical line-up which automatically suggests a historical directionality; either in the way order or organization comes about, going from lower levels in a hierarchy to higher levels, or by undergoing major restructuring in biological organization at different levels in a hierarchy (that in turn coincide with the hypothesized transitions).

This special issue exemplifies these intriguing problems with three contributions. McShea starts with pointing out the relationships that exist among complexity, hierarchy, transitions and trends and goes on to delineate three major trends in complexity; Guerrero and Berlanga use biophysical, ecological systems theoretical, and symbiological jargon to describe how biogenesis is characterized by autopoiesis, ecopoiesis and symbiogenesis which can also be considered trends or patterns in natural history; and the article by Watson and coworkers is a continuation of the framework first introduced by Maynard Smith and Szathmáry on major transitions.

McShea distinguishes three large-scare trends in complexity: (1) complexity can increase vertically, which involves a rise in structural complexity where parts become embedded into wholes that form an increasingly nested hierarchy; (2) complexity can increase horizontally, which involves a numerical differentiation at the focal level (the level below the whole); and (3) complexity can become drained at the lowest levels of a nested hierarchy, as a result of which differentiation and autonomy of the parts is lost in favor of the "machinification" of the lowest levels. In other words, once nested hierarchies become formed, focal levels of that hierarchy first go through a division of labor which results in differentiation, and this differentiation eventually leads to a loss of autonomy of the individual parts, in favor of a machinification of those lower levels in function of the whole. The first large-scale trend resembles the so-called major transitions of Maynard Smith and Szathmáry who define the transitions based upon information storage driven by selection. In contrast, McShea gives a structural definition of complexity (Simon 1962).

McShea list numerous examples of these recurring patterns in how complexity comes about. When, for example, individual prokaryotic cells integrate into eukaryotic cells, the eukaryotic cell becomes more complex and differentiated into various structures, but during symbiogenesis, integrated prokaryotic cells underwent gene loss and subsequently lost their autonomy disabling them for survival outside the cell and instead evolved into organelles where they function as eukaryotic cell "machine parts." The functions performed by the organelles become more streamlined in function of the eukaryotic cell, a process that is also analyzed by Guerrero and Guerrerro.

In a second part of his paper, McShea investigates the possibility of finding mechanistic explanations for these trends. In the first trend, a higher-level object is formed from lower-level objects, but such can be a mere outcome of a rising maximum and the trend could be merely passive. The second trend always occurs at the focal level of a hierarchy and can be causally explained by the zero-force law (McShea and Brandon 2010) which can be driven by selection for complexity or simply by the accumulation of differences. The third trend is explained by selection favoring the whole, thereby streamlining or stabilizing the system. The three trends are framed in an increasingly nested hierarchy and the author suggests the trends lend insight into a repetitive causal cascade.

The phenomenon of symbiosis is not confined to the origin of eukaryotic organelles which happened 2 billion years ago, but is it a trend or recurring pattern in evolution? This is the basic question raised by Guerrero and Berlanga who answer in the affirmative. Biogenesis or the origin of life is characterized by three major trends: autopoiesis, ecopoiesis and symbiogenesis. Autopoiesis refers to the capacity of organisms to self-maintain and reproduce while ecopoiesis is the process whereby organisms interact with their habitats in such a way that they selectively take up compounds that enable them to self-maintain and excrete metabolic products that in turn modify the environment. Both autopoiesis and ecopoiesis lead to metabolic connectivity between organisms which in turn drives symbiogenesis.

Obligate symbiotic co-evolved dependencies characterize the transition from pro- to eukaryotes where individual bionts (prokaryotes, the minimal unit of autopoiesis) unite and form holobionts (integrated bionts) that demonstrate a "higher functional-structural complexity". Eukaryotic organelles, while once bacteria themselves, have lost their auto- and ecopoietic abilities and contribute to the autoand ecopoiesis of the holobiont.

Guerrero and Berlanga demonstrate that such characterizations can also be applied to population and community formation (biocenosis) in prokaryotes. Single prokaryotes are rarely found in nature. Instead they form complex multi-species communities (consortia) such as microbial mats and other biofilms. Consortia are the minimal ecological unit that enables bacteria to sustain and the authors list the basic principles or patterns that underlie biocenosis. Individual bacterial adaptations are driven by competition for nutrients, motility requirements, and antibiotic resistance and these factors promote growth and reproduction. At an ecological level, growth and reproduction result in population formation and environmental 
success becomes determined by an organism's ability to avoid, tolerate or defend against other individuals. Populations in turn deplete nutrients and accumulate waste which causes for differentiation amongst the populations which induces community formation. The authors go on to demonstrate how prokaryotic consortia are responsible for chemical gradient formation that underlies the major redox (reduction-oxidation) reactions essential for all subsequently evolved life forms, and how they establish the biogeochemical cycles.

Continuing the work on major transitions, the first question Watson and coworkers ask, is given the major transitions that have occurred-going from self-replicating molecules to chromosomes to unicellular to multi-organelle eukaryotic cells to multicellular to eusocial groups-what is common to all? Their answer is that all levels of biological organization operate along the Darwinian principles (differential variation, inheritance, and fitness/selection). Their second question is how the Darwinian principles operating at one level of biological organization become recursively repeated at a higher level. The authors begin their paper with examining how evodevo has altered our ideas on variation by introducing notions such as evolvability; evo-eco has changed how we understand the nature of the selective environment by introducing ideas on ecosystem-levels of organization; and discussions on biological individuality, what they call evoego, have made us re-interpret the heritability of the evolutionary unit.

Variation, individuality and environmental selection are not fixed but are altered by developmental, reproductive, and ecological network-like relations that introduce affordances and constraints on how a system can evolve. Modelling these network-like relations or "evolutionary connectionism" as the authors call it, is mathematically isomorphic to how scholars have modelled the evolution of learning systems. Following Hebb's (1949) learning metaphor that states that "neurons that fire together wire together" the authors examine how genes that are selected together are wired together in gene-regulatory networks (evo-devo); how two species that evolve in high density together will strengthen ecological interactions; and the more evolutionary units reproduce together, the more reproductive dependencies arise between them. These ecological interactions and reproductive dependencies include symbiosis and holobiont formation, which is also discussed by Guerrero and Berlanga as well as Sapp and Casiraghi et al. "Correlation becomes causation" and evolution alters which elements vary together (which gives rise to a network that becomes an evolutionary unit), are selected together (which leads to a network containing multiple units), and are inherited together (the emergence of a new biological individual out of a previous network) leading to a positive feedback between evolutionary processes and structural organizations that results in the transformation and recreation of the Darwinian principles at a higher level.

This characterization has implications for how we understand natural selection. For one, it is a self-referential system meaning that selection operating at a focal level will alter how selection will occur at a higher level; and secondly, given the functional analogy with learning systems, natural selection itself can, as scholars such as Campbell (1959, 1960, 1974a) and Riedl $(1977,1984)$ noted before, be understood as a learning mechanism without working with any foresight. The higher-level system emerges from selection operating at a lower level, and what becomes selected are interactional patterns rather than entities.

The authors agree, natural history is characterized by a recursive pattern where independent entities combine and form new structures whereafter the individual components lose autonomy. But it is intriguing how they use different theoretical frameworks and a variety of mechanisms to describe and explain the pattern in and of itself as well as its repetition at various scales. While from an ontological point of view it lends plausibility to the actual existence of the pattern, from an epistemological point of view it requires us to take on a more pluralistic stance on the nature whereby evolutionary change comes about, at least until a synthetic view is proposed that is able to combine these diverse theories.

\section{Natural Kinds, Biological Individuals and the Units of Evolution}

Any and all patterning of our observations and data into scientific theories on the evolutionary trajectories taken by natural kinds in history requires us to distinguish units (structures) from their level in a hierarchy or location in the "real" world, and to determine the amount of randomness or determinism by which these units and levels came about (mechanisms) (Gontier 2010). The Darwinization of the biological, linguistic and sociocultural sciences has been accompanied with the units and levels of selection debate (Lewontin 1970, Brandon 1982), a debate that associates with inquiries into the nature and individuality of natural kinds (Ghiselin 1974; Hull 1980) and with finding the "logical skeleton" (Lewontin 1970) or "universal heuristic" (Campbell 1974a) of natural selection in order for the theory to be applicable to phenomena beyond genes such as linguistic and sociocultural phenomena (Dawkins 1976).

Beyond natural selection, scholars today distinguish numerous evolutionary processes and mechanisms, including transformation, transduction, bacterial conjugation, gene transfer agents and the movement of mobile 
genetic elements that induce lateral gene flow (Lederberg 1952; Syvanen 1985; Doolittle 1999; Koonin et al. 2001; Keeling and Palmer 2008; Woese 2004); hybridization and introgression (Anderson and Stebbins 1954; Barton 1979; Arnold et al. 2012); (hereditary) symbiosis that induces evolution by symbiogenesis (Sagan 1967; Margulis 1970; Bonen and Doolittle 1975, 1977; Zilber-Rosenberg and Rosenberg 2008; Hotopp 2011; Brucker and Bordenstein 2012); genetic and ecological drift (Kimura 1968, 1983; Hubbel 2001); and epigenetic and developmental mechanisms and processes (McGinnis et al. 1984; Levins and Lewontin 1985; Gould 1977; Gehring 1992; Goodwin and Saunders 1992; Jablonka and Lamb 1995; Oyama et al. 2001; Odling-Smee et al. 2003; West-Eberhard 2003; Gilbert and Epel 2008; Pigliucci and Müller 2010; Minelli and Pradeu 2014).

Any and all of these findings have introduced new units, not merely of selection but of evolution as it proceeds by non-Darwinian mechanisms. This requires extended views on how we define evolutionary individuals and the information they contain and transmit, and it requires us to differentiate numerous additional levels within the individual itself, and its biotic and abiotic environment with which it interacts. The old units and levels of selection debate is therefore better characterized as the units, levels, and mechanisms of evolution debate (Gontier 2010).

We already reviewed how Mesoudi, and Bradie and Bouzat define and analyze cultural information, and Kressing, de Voogt, and Morrison review how this cultural information becomes transmitted. Guerrero and Berlanga's work on autopoiesis, ecopoiesis and symbiogenesis and the associated emergence of holobionts; McShea's work on trends in complexity and hierarchy formation; and the contribution of Watson et al., in particular in what regards the various transitions in evo-ego they discuss, all have implications for the units and levels of evolution debate, how we can determine the mechanisms whereby these units evolve at multiple levels of a hierarchy, and how higherlevels of biological individuality come about. Here, we focus on the contributions authored by Sapp, and Casiraghi and co-authors, who review how especially reticulate evolutionary theories, backed up by incoming data from molecular genetic analyses, requires us to reconsider our notions on biological individuality at an organismal and species level.

Genes are major causal factors in the formation of morphological structures which in turn enables us to distinguish organisms and species from one another. Today however, organisms and the species they belong too, are often identified and reduced to the genes they possess, because each organism is argued to have a unique genetic code, and to share more genes in common with its kin and its own species then with others. In (meta-)barcoding techniques (Hebert et al. 2003), for example, genes become the exclusive measurement of distance between species.

Casiraghi and co-authors examine definitions of life, they give an impressive list of the various species concepts currently in use, and they examine the nature of organisms and biological individuals in light of data acquired from (next-generation) high throughput DNA-sequencing techniques. Pedigrees and trees are nowadays exclusively build upon shared gene sets, but while genetic homogeneity is somewhat straightforward amongst eukaryotes taxa, prokaryotes demonstrate genetic diversity both inter- and intra-specifically. Lateral gene transfer disrupts vertical transmission of the genetic code, making the transferrable genes less-suited candidates to define and separate individuals and species from one another. Instead, organisms such as E. coli appear to consist of a mosaic of various genomes. And if living organisms are defined by their genetic code, then Casiraghi et al. note, size cannot be included as a defining feature because there exist viruses, such as mega-viruses, that possess a larger genome than some organisms.

As noted by Kolb, viruses are generally considered nonliving organisms because they are dependent upon a host for replication, but Casiraghi and co-authors note that intracellular symbionts are considered living entities, while just like viruses they often depend upon their host for selfmaintenance and reproduction. Organelles also roam the transition zone between the living and the dead, having evolved from once free-living bacteria to subcellular dead structures. Organellar evolution is also not confined to the past, the currently smallest know intracellular symbionts, i.e. Candidatus cicadicola found inside the insect Diceroprocta semicincta, are also bacteria presumed to be in the process of transitioning to organelles.

In the final part of their paper, the authors extend their analysis to the notion of biological individuality and note that in general, three criteria are used to define it: genetic uniqueness, genetic homogeneity, and autonomy or physiological independence. Huxley defined the individual organism as any animal form that has a single life. On that account a caterpillar is part of the same biological individual as the butterfly even though they undergo transformations, and such identity, in the form of genetic uniqueness, can today be measured by genes. But monovular twins share the same genome although their life path is different, and genes therefore cannot function as the sole criteria to define genetic uniqueness. Other examples discussed by the authors include mutagenesis and metamorphosis, somatic and germ cells, and processes of symbiosis and symbiogenesis that, on a higher level of a biological hierarchy, give way to "superorganisms" or "holobionts" that comprise a biological individual with multiple genomes and thus, as Zilber-Rosenberg and 
Rosenberg (2008) call it, a hologenome. In such a higher entity, the authors point out, autonomy, the third criterion used to define biological individuality, also becomes problematic.

Any and all reasoning on biological individuality needs to invoke stances on parts and wholes, as well as how they hierarchically relate to one another, in an either sequential or embedded matter. Holobionts are examples par excellence of higher-order individuals that embed smaller individual bionts into new entities through the process of hereditary symbiosis. Sapp examines how all eukaryotic organisms are multi-genomic entities. Symbiosis obliges us to re-conceptualize the presumed linear order scholars have detected in time, because, as Sapp opens his article: "We are genetic and physiological chimeras. We did not just evolve from bacteria, we have evolved with them" (my italics). By building on Margulis and Guerrero's definition, Sapp defines the holobiont as the host and its microbial community that includes all symbiotic viruses and microorganisms, while following the Rosenberg's, the hologenome is defined by the sum of all genomes present in the host (its own as well as those of its viral and microbial community). Sapp urges for a new understanding of the biological individual as a "dynamic, multispecies community-based" entity.

The author contributes a rich historical overview of the context wherein symbiosis research evolved, and critically analyzes the recent literature on holobiont and hologenome selection. He concludes that the holobiont is not merely a co-evolved and cooperating superunit, both the holobiont and its components evolve by a variety of mechanisms, and thus all are possible units, not merely of selection, but also of hereditary symbiosis and drift.

Sapp goes on to demonstrate the relevance of "symbiomics" over "genomics" in understanding evolution, ecology, physiology, morphogenesis and the behavior of biological organisms. Incoming data on the role the microbiological world plays in health and disease, by and large acquired by molecular techniques, no longer make it tenable that "germs" straightforwardly correlate to disease.

\section{Concluding Remarks and Future Directions}

From an epistemic point of view, process and pattern have often been polarized in association with a favoring of micro-versus macro-oriented levels of analysis, synchronic versus diachronic research, and reductionism versus holism. Process and pattern debates furthermore associate with discussions on ontogeny versus phylogeny, the use of tree versus network analyses, and whether the goal of science is to provide descriptions of how the world is, or to explain why it is the way it is. What this special issue makes clear most of all is that there exists an intrinsic relation between pattern and process and the same goes for all other dichotomies. One can prefer to analyze a subject matter from within one particular stance, but one cannot theorize either stance without the other. That is true for all binary oppositions, and over the years, we have reconceptualized the oppositions as two extreme ends of a long spectrum.

While debates have run high in the past, today, we are reaching an era where scholars are more willing to cross their classic disciplinary boundaries, and they do so with good reason. None of the various approaches used to study evolution are more or less scientific, and tenets in all schools of thought have either been proven by observations or experiments, or they have so far not been falsified. In the end, the various approaches necessitate a pluralistic view on evolution. A pluralistic view on particular subjects in turn enables us to take on a comparative stance which only benefits insight into the problem. And such a comparative investigation might on a higher level itself serve as a means to unify the sciences.

Secondly, it is interesting to find out that no matter how different the epistemological framework one works in, and regardless of whether one studies biological or sociocultural evolution, from a micro- or macrolevel of analysis, and focusing either on vertical or reticulate evolution, there remains a core of problems that all scholars want to solve. Beyond defining the subject area (what is life, culture, language, or how do we define species, organisms or sociocultural traits), scholars attempt to discover the units, levels and mechanisms of evolution, how we define information exchange, and how these elements, loci and processes organize themselves in nature as well as how they interact. In other words, there does exist a core set of problems that is inherent to all evolutionary sciences. But because scholars have been working from within different schools of thought, and at different levels of the hierarchical scale, this core set of problems has seldom been defined or taken as point of analysis in and of itself. Establishing such a framework would be beneficial for all fields involved.

Nonetheless, it is fair to say that a majority of scholars active in both the sociocultural and biological research community have long favored reductionist, mechanical, functional-structuralist and micro- or mesolevel analyses and explanations. Current debates on the scope and adequacy of the modern synthesis, or the "Darwinization" or incorporation of general evolutionary thought within the sociocultural sciences is accompanied with an incorporation of more holistic, ecological, ontogenetic, and macrolevel analyses and with new means to model not only the entities but the interactions and transitions between them. Given that at the onset of evolutionary thought, in the nineteenth century, biologists, anthropologists and linguists 
already averred the implementation of evolutionary thought to understand these phenomena, we are left with the question why early attempts failed, and why the community has long resisted them.

Numerous authors in this volume discuss the unilinealism or orthogenetic views presented in early biological and sociocultural schools of thought, as well as the difficult nature associated with incorporating ontogeny, ecology or symbiology into the standard paradigm. Gontier provides an additional reason for why such incorporation was difficult. Non-paradigmatic evolutionary models associated with an extended synthesis endorse different notions on causality, and these notions derive from different ways in how we can conceptualize time and space.

She first investigates how our species has conceptualized time and space and distinguishes four different cosmologies and three major transitions in time thinking. Time was originally considered to be cyclical, later it was understood to be linear and absolute and today, in physics, time is conflated with space into a single space-time continuum which questions the very existence of time while there exists a somewhat consensus view amongst philosophers, neurocognitive scientists and linguists that the capacity to experience time is a cognitively evolved trait. In association, space was conceptualized as the locus where change occurred, and change was understood as the movement of matter in space and time.

The evolutionary sciences find their origin in natural history research, an enterprise that was fascinated with the problem of time. Following classical Aristotelian physics, time was defined as matter in motion, and following Descartes, causality was defined as linear. Linear time-thinking enabled early history scholars to use the sequential line-up of fossils in the consecutive layers of the earth's strata to define the evolution of species, while the historical succession of languages and cultures defined the evolution of the sociocultural domain. It is the natural history scholars' notion of time that enabled the introduction of diachronically oriented (dating) studies into the origin of natural kinds.

The author demonstrates how different notions of time bring forth different notions of causality and how they generate different means to model and calculate the evolutionary distance between natural kinds. Both time and causality have for the most part of history been considered unidirectional and unilineal, and both concepts enable for uniformitarian and mechanical explanations on how species evolve, as well as linear timelines and phylogenetic tree models that demonstrate vertical patterns of evolution.

The different ideas associated with an extended synthesis underlie different time notions. Fields such as ecology, symbiology and evo-devo investigate processes such as emergence, reversed directionality, up- and downward causation that occur in the present, and such horizontal interactions induce perturbations in otherwise unilineal systems that are modelled by making use of networks and non-linear dynamic system theories. These approaches also mark shifts from mechanical to statistical thinking, because the number of parameters that are taken into account to calculate change become so numerous that straightforward predictions for future change are near to impossible. Tree to network modelling, mechanical to statistical thinking, and genealogy to economy thinking is underlain by different notions of time; and these transitions in epistemological approaches associate with the introduction of new parameters that are used to time evolutionary events; from the earth's strata and natural historical events to molecular clocks, the organisms themselves and the interactions they entertain.

Acknowledgments Work on this special issue was integrally funded by the Portuguese Foundation for Science and Technology (Fundação para a Ciência e a Tecnologia, Grant ID SFRH/BPD/89195/2012 and project ID UID/FIL/00678/2013). We cordially thank Benedikt Hallgrímsson for providing us with an excellent home for this issue, and the authors for contributing. All of us also extend our outspoken gratitude to Eveline Kolijn for the beautiful artistic cover to this volume. More information on evolutionary patterns can be found at http://evolutionarypatterns.campus.ciencias.ulisboa.pt/ and https:// www.youtube.com/user/appeellisboa/playlists, where symposia and talks are featured that were presented at the International Conference on "Evolutionary Patterns: Horizontal and Vertical Transmission and Micro- and Macro-evolutionary Patterns of Biological and Sociocultural Evolution". The conference was sponsored by the Portuguese Calouste Gulbenkian Foundation, the John Templeton Foundation (Grant ID 36288), and the Applied Evolutionary Epistemology Lab of the Centre for Philosophy of Science of the University of Lisbon, Portugal.

\section{Compliance with Ethical Standards}

Conflict of interest The author declares to have no conflicts of interest.

\section{References}

Abouheif, E., Favé, M. J., Ibarrarán-Viniegra, A. S., Lesoway, M. P., et al. (2014). Eco-evo-devo: The time has come. Advances in Experimental Medicine and Biology, 781, 107-125.

Allen, T. F. H., \& Starr, T. B. (1982). Hierarchy: Perspectives for ecological complexity. Chicago, IL: University of Chicago Press.

Anderson, E., \& Stebbins, G. L. (1954). Hybridization as an evolutionary stimulus. Evolution, 8, 378-388.

Arnold, M. L., Ballerini, E. S., \& Brothers, A. N. (2012). Hybrid fitness, adaptation and evolutionary diversification: Lessons learned from Irises, Louisiana. Heredity, 108, 159-166.

Atkinson, Q. D. (2010). The prospects for tracing deep language ancestry. Interdisciplinary views on molecular anthropology in the genomic era. Journal of Anthropological Sciences, 88, 231-233.

Avery, O. T., Macleod, C. M., \& McCarty, M. (1944). Studies on the chemical nature of the substance inducing transformation of pneumococcal types. Induction of transformation by a deoxy- 
ribo-nucleic acid fraction isolated from pneumococcus type III. Journal of Experimental Medicine, 79, 137-157.

Ayala, F. J. (1970). Teleological explanations in evolutionary biology. Philosophy of Science, 37(1), 1-15.

Barton, N. H. (1979). Gene flow past a cline. Heredity, 43, 333-339.

Beadle, G. W., \& Tatum, E. L. (1941). Genetic control of biochemical reactions in Neurospora. Proceedings of the National Academy of Science, USA, 27(11), 499-506.

Benton, M. (2009). Paleontology and the history of life. In M. Ruse \& J. Travis (Eds.), Evolution: The first four billion years (pp. 80-104). Cambridge, MA: The Belknap Press of Harvard University Press.

Blum, H. F. (1951). Time's arrow and evolution. Princeton, NJ: Princeton University Press.

Boas, F. (1940). Race, language, and culture. New York: The Macmillan Company.

Bonen, L., Cunningham, R. S., Gray, M. W., \& Doolittle, W. F. (1977). Wheat embryo mitochondrial 18S ribosomal RNA: Evidence for its prokaryotic nature. Nucleic Acids Research, 4(3), 663-671.

Bonen, L., \& Doolittle, W. F. (1975). On the prokaryotic nature of red algal chloroplasts. Proceedings of the National Academy of Sciences, USA, 72(6), 2310-2314.

Borde, A., Guth, A., \& Vilenkin, A. (2003). Inflationary spacetimes are incomplete in past directions. Physical Review Letters, 90(15), 151301

Boyd, R., \& Richerson, P. J. (1985). Culture and the evolutionary process. Chicago, IL: The University of Chicago Press.

Bradie, M. (1986). Assessing evolutionary epistemology. Biology and Philosophy, 1, 401-459.

Brandon, R. N. (1982). The levels of selection. In R. N. Brandon, R. M. Burian (Eds.), Genes, organisms, populations: Controversies over the units of selection 1984 (pp. 133-139). Cambridge MA: MIT

Brucker, R. M., \& Bordenstein, S. R. (2012). Speciation by symbiosis. Trends in Ecology and Evolution, 27, 443-451.

Cairns, J., Overbaugh, J., \& Miller, S. (1988). The origin of mutants. Nature, 335(6186), 142-145.

Campbell, D. T. (1959). Methodological suggestions from a comparative psychology of knowledge processes. Inquiry, 2(3), 152-183.

Campbell, D. T. (1960). Blind variation and selective retention in creative thought as in other knowledge processes. Psychological Reviews, 67, 380-400.

Campbell, D. T. (1965). Variation and selective retention in sociocultural evolution. In R. Herbert, G. Barringer, I. Blanksten, \& R. W. Mack (Eds.), Social change in developing areas: A reinterpretation of evolutionary theory (pp. 19-49). Cambridge, MA: Schenkman.

Campbell, D. T. (1974a). Evolutionary epistemology. In P. A. Schilpp (Ed.), The philosophy of Karl Popper (pp. 413-463). LaSalle, IL: Open Court.

Campbell, D. T. (1974b). 'Downward causation' in hierarchically organized biological systems. In F. J. Ayala \& T. Dobzhansky (Eds.), Studies in the philosophy of biology (pp. 179-186). London: Macmillan.

Campbell, D. T. (1997). From evolutionary epistemology via selection theory to a sociology of scientific validity; Edited by Cecilia Heyes and Barbara Frankel. Evolution and Cognition, 3(1), 5-38.

Carroll, S. B., Grenier, J. K., \& Weatherbee, S. D. (2005). From DNA to diversity: Molecular genetics and the evolution of animal design (2nd ed.). Malden, MA: Blackwell.

Cavalli-Sforza, L. L., \& Feldman, M. W. (1981). Cultural transmission and evolution: A quantitative approach. Princeton, NJ: Princeton University Press.
Cech, T. R., et al. (1982). Transcription and splicing of the ribosomal RNA precursor of Tetrahymena. In H. Busch \& L. Rothblum (Eds.), The cell nucleus (pp. 171-204). New York: Academic press.

Claidière, N., \& Sperber, D. (2007). The role of attraction in cultural evolution. Journal of Cognition and Culture, 7(2), 89-111.

Conway Morris, S. (2003). Life's evolution: Inevitable humans in a lonely universe. Cambridge UK: Cambridge University Press.

Crick, F. (1968). The origin of the genetic code. Journal of Molecular Biology, 38, 367-379.

Croft, W. (2000). Explaining language change: An evolutionary approach. Essex: Pearson.

Croft, W. (2002). The Darwinization of linguistics. Selection, 3(1), 75-91.

Curnoe, D., Ji, X., Taçon, P. S., \& Yaozheng, G. (2015). Possible signatures of hominin hybridization from the early Holocene of southwest China. Scientific Reports, 5, 12408. doi:10.1038/ srep12408.

Darwin, C. (1859). On the origin of the species by means of natural selection: Or, the preservation of favored races in the struggle for life. London: John Murray.

Dawkins, R. (1976). The selfish gene. Oxford: Oxford University Press.

de Saussure, F. (1916). Cours de linguistique générale; C. Bally \& A. Sechehaye. Paris: Payot.

Dobzhansky, T. (1973). Nothing in biology makes sense except in the light of evolution. The American Biology Teacher, 35, 125-129.

Doolittle, W. F. (1999). Phylogenetic classification and the universal tree. Science, 284(5423), 2124-2129.

Dunny, G. M., Brickman, T. J., \& Dzorkin, M. (2008). Multicellular behavior in bacteria: Communication, cooperation, competition and cheating. BioEssays, 30, 296-298.

Durkheim, É. (1922). Éducation et sociologie. Paris: Les Presses universitaires de France.

Eddington, A. (1928). The nature of the physical world. London: MacMillan.

Eigen, M. (1971). Selforganization of matter and the evolution of biological macromolecules. Die Naturwissenschaften, 58(10), 465-523.

Eldredge, N. (1985). Unfinished synthesis: Biological hierarchies and modern evolutionary thought. Oxford: Oxford University Press.

Eldredge, N. (1999). The pattern of evolution. New York: Freeman.

Eldredge, N., \& Cracraft, J. (1980). Phylogenetic analysis and the evolutionary process. New York: Columbia University Press.

Eldredge, N., \& Gould, S. J. (1972). Punctuated equilibria: An alternative to phyletic gradualism. In T. J. M. Schopf (Ed.), Models in paleobiology (pp. 82-115). San Francisco, CA: W.H. Freeman.

Fox, S. W., \& Dose, K. (1977). Molecular evolution and the origin of life. New York: Marcel Dekker.

Fox, C. W., Roff, D. A., \& Fairbairn, D. J. (2001). Evolutionary ecology: Concepts and case studies. Oxford: Oxford University Press.

Futuyma, D. (2015). Can modern evolutionary theory explain macroevolution? In E. Serrelli \& N. Gontier (Eds.), Macroevolution (pp. 29-85). Dordrecht: Springer.

Gehring, W. J. (1992). The homeobox in perspective. Trends in Biochemical Sciences, 17(8), 277-280.

Ghiselin, M. (1974). A radical solution to the species problem. Systematic Zoology, 23, 536-544.

Gilbert, W. (1986). The RNA world. Nature, 319(6055), 618.

Gilbert, S. F., \& Epel, D. (2008). Ecological developmental biology: Integrating epigenetics, medicine and evolution. Sunderland, MA: Sinauer.

Gontier, N. (2006a). Evolutionary epistemology. In J. Fieser, B. Dowden \& J. Beebe (Eds.), The internet encyclopedia of philosophy. http://www.iep.utm.edu/e/evo-epis.htm. 
Gontier, N. (2006b). Evolutionary epistemology and the origin and evolution of language: Taking symbiogenesis seriously. In N. Gontier, J. P. Van Bendegem, \& D. Aerts (Eds.), Evolutionary epistemology, language and culture: A non-adaptationist systems theoretical approach (pp. 195-226). Dordrecht: Springer.

Gontier, N. (2010). Evolutionary epistemology as a scientific method: A new look upon the units and levels of evolution debate. Theory in Biosciences, 129(2-3), 167-182.

Gontier, N. (2011). Depicting the tree of life: the philosophical and historical roots of evolutionary tree diagrams. Evolution: Education and Outreach, 4(515), 538.

Gontier, N. (2012). Applied evolutionary epistemology: A new methodology to enhance interdisciplinary research between the life and human sciences. Kairos: Revista de Filosofia and Ciência, 4, 7-49.

Gontier, N. (2015a). Reticulate evolution everywhere. In N. Gontier (Ed.), Reticulate evolution (pp. 1-38). Dordrecht: Springer.

Gontier, N. (2015b). Uniting micro- with macroevolution into an extended synthesis: Reintegrating life's natural history into evolution studies. In E. Serrelli \& N. Gontier (Eds.), Macroevolution: Explanation, interpretation and evidence (pp. 227-278). Dordrecht: Springer.

Gontier, N., Bradie, M. (forthcoming). Acquiring knowledge on species-specific biorealities: The applied evolutionary epistemological approach. In R. Joyce (Ed.), Routledge handbook of evolution and philosophy. London: Routledge.

Gontier, N., Van Bendegem, J. P., \& Aerts, D. (Eds.). (2006). Evolutionary epistemology, language and culture: A non-adaptationist systems theoretical approach. Dordrecht: Springer.

Goodwin, B. C., \& Saunders, P. (1992). Theoretical biology: Epigenetic and evolutionary order from complex systems. Baltimore: Johns Hopkins University Press.

Gould, S. J. (1977). Ontogeny and phylogeny. Cambridge, MA: The Belknap Press of Harvard University Press.

Gould, S. J. (1981). Mismeasure of man. New York: Norton \& Company.

Gould, S. J. (1988). Trends as changes in variance: A new slant on progress and directionality in evolution. Journal of Paleontology, 62, 319-329.

Gould, S. J. (1989). Wonderful life. New York: W.W. Norton and Company.

Gould, S. J., \& Lewontin, R. C. (1979). The spandrels of San Marco and the panglossian paradigm: a critique of the adaptationist programme. Proceedings of the Royal Society, London, 205, 581-598.

Gray, R. D., \& Jordan, F. M. (2000). Language trees support the express-train sequence of Austronesian expansion. Nature, 405, 1052-1055.

Green, R. E., Krause, J., Briggs, A. W., Maricic, T., Stenzel, U., Kircher, M., et al. (2010). A draft sequence of the Neanderthal genome. Science, 328(5979), 710-722.

Gruner, R. (1969). Uniqueness in nature and history. The Philosophical Quarterly, 19(75), 145-154.

Guerrier-Takada, C., Gardiner, K., Marsh, T., Pace, N., \& Altman, S. (1983). The RNA motility of ribonuclease P is the catalytic subunit of the enzyme. Cell, 135, 849-857.

Haeckel, E. (1866). Generelle Morphologie der Organismen (2 volumes). Berlin: Georg Reimer.

Haeckel, E. (1917). Kristallseelen, studien über das Anorganische Leben. Leipzig: Alfred Kroner Verlag.

Hall, B. K. (1999). Evolutionary developmental biology. The Netherlands: Kluwer.

Harte, V. (2002). Plato on parts and wholes: The metaphysics of structure. Oxford: Oxford University Press.

Hebb, D. O. (1949). The organization of behavior. New York: Wiley.
Hebert, P., et al. (2003). Biological identifications through DNA barcodes. Proceedings of the Royal Society B, 270, 313-321.

Hotopp, J. C. D. (2011). Horizontal gene transfer between bacteria and animals. Trends in Genetics, 27(4), 157-163.

Hubbell, S. P. (2001). The unified neutral theory of biodiversity and biogeography. Princeton, NJ: Princeton University Press.

Hull, D. L. (1980). Individuality and selection. Annual Review of Ecology and Systematics, 11, 311-332.

Husserl, E. (1928). Vorlesungen zur Phänomenologie des inneren Zeitbewusstseins. Niemeyer: Halle a.S.

Hutton, J. (1788). Theory of the earth; or an investigation of the laws observable in the composition, dissolution, and restoration of land upon the globe. Transactions of the Royal Society of Edinburgh, 1, 209-304.

Huxley, J. (1942). Evolution: The modern synthesis. London: Allen and Unwin.

Huxley, J. (1957). The three types of evolutionary process. Nature, 180, 454-455.

Jablonka, E., \& Lamb, M. J. (1995). Epigenetic inheritance and evolution: The Lamarckian dimension. London: Oxford University Press.

Jacob, F., \& Monod, J. (1961). Genetic regulatory mechanisms in the synthesis of proteins. Journal of Molecular Biology, 3, 318.

Kauffman, S. A. (1971). Cellular homeostasis, epigenesis, and replication in randomly aggregated macromolecular systems. Journal of Cybernetics, 1, 71-96.

Kauffman, S. A. (2011). Approaches to the origin of life on earth. Life, 1(1), 34-48.

Kay, L. E. (1996). The molecular vision of life. London: Chapman \& Hall.

Keeling, P. J., \& Palmer, J. D. (2008). Horizontal gene transfer in eukaryotic evolution. Nature Reviews Genetics, 9(8), 605-618.

Kimura, M. (1968). Evolutionary rate at the molecular level. Nature, $217,624-626$.

Kimura, M. (1983). The neutral theory of molecular evolution. Cambridge: Cambridge University Press.

Koestler, A. (1967). The ghost in the machine. New York: Macmillan.

Koonin, E. V., Makarova, K. S., \& Aravind, L. (2001). Horizontal gene transfer in prokaryotes: Quantification and classification. Annual Review of Microbiology, 55(1), 709-742.

Kroeber, A. (1923). Anthropology. New York: Harcourt and Brace.

Kuhn, T. S. (1962). The structure of scientific revolutions. Chicago, IL: Chicago University Press.

Laland, K., Wray, G. A., Hoekstra, H. E., et al. (2014). Does evolutionary theory need a rethink? Nature, 514, 161-164.

Lederberg, J. (1952). Cell genetics and hereditary symbiosis. Physiological Reviews, 32(4), 403-430.

Levins, R., \& Lewontin, R. (1985). The dialectical biologist. London: Harvard University Press.

Levinton, J. S., \& Futuyma, D. J. (1982). Macroevolution: Pattern and process introduction and background. Evolution, 36, 425-473.

Lewontin, R. C. (1970). Units of selection. Annual Review of Ecology and Systematics, 1, 1-18.

Lorenz, K. (1941). Kants Lehre vom Apriorischen im Lichte gegenwärtiger Biologie. Blätter für Deutsche Philosophie, 15, 94-125.

Lorenz, K. (1958). The evolution of behavior. Scientific American, 199(6), 67-78.

Lorenz, K. (1977). Behind the Mirror. London: Methuen.

Lorenz, K. (1985). Wege zur Evolutionären Erkenntnistheorie. In A. Ott, G. Jörg, P. Wagner, \& F. Wuketits (Eds.), Evolution, Ordnung und Erkenntnis (pp. 13-20). Heidelberg: Springer.

Love, A. C. (2003). Evolutionary morphology, innovation, and the synthesis of evolutionary and developmental biology. Biology and Philosophy, 18, 309-345. 
Malinowski, B. (1922). Ethnology and the study of society. Economica, 2, 208-219.

Malinowski, B. (1945). The dynamics of culture change. Connecticut, NH: Yale University Press.

Margulis, L. (1970). Origin of eukaryotic cells. Connecticut, NH: Yale University Press.

Margulis, L., \& Sagan, D. (2000). What is life. Berkeley, CA: University of California Press.

Marx, K. (1890). Das Kapital, Kritik der politschen Oekonomie. Buch 1: Der Produktionsprocess des Kapitals. 4th edition, reprinted by Friedrich Engels. Hamburg: Verlag von Otto Meisner.

Mayhew, P. J. (2006). Discovering evolutionary ecology: Bringing together ecology and evolution. New York: Oxford University Press.

Maynard Smith, J., \& Szathmáry, E. (1995). The major transitions in evolution. New York: Oxford University Press.

Mayr, E. (1942). Systematics and the origin of species. New York: Columbia University Press.

Mayr, E. (1961). Cause and effect in biology: Kinds of causes, predictability, and teleology are viewed by a practicing biologist. Science, 134(3489), 1501-1506.

McGinnis, W., Levine, M. S., Hafen, E., Kuroiwa, A., \& Gehring, W. J. (1984). A conserved DNA sequence in homoeotic genes of the Drosophila Antennapedia and bithorax complexes. Nature, 308(5958), 428-433.

McNamara, K. J. (Ed.). (1990). Evolutionary trends. Tuscan, AZ: University of Arizona Press.

McShea, D. W. (1998). Possible largest-scale trends in organismal evolution: Eight live hypotheses. Annual Review of Ecology and Systematics, 29, 293-318.

McShea, D. W. (2001). Evolutionary trends. In D. E. G. Briggs \& P. R. Crowther (Eds.), Palaeobiology (pp. 206-211). Oxford: Blackwell Science.

McShea, D. W., \& Brandon, R. N. (2010). Biology's first law. Chicago, IL: University of Chicago Press.

Miller, S. L. (1953). Production of amino acids under possible primitive earth conditions. Science, 117(3046), 528-529.

Minelli, A., \& Pradeu, T. (Eds.). (2014). Toward a theory of development. Oxford: Oxford University Press.

Müller, G. (2007). Evo-devo: Extending the evolutionary synthesis. Nature Reviews Genetics, 8, 943-949.

Munz, P. (1993). Philosophical Darwinism: On the origin of knowledge by means of natural selection. London: Routledge.

Nadell, C. D., Xavier, J. B., \& Foster, K. R. (2009). The sociobiology of biofilms. FEMS Microbiological Reviews, 33(1), 206-224.

Nelson-Sathi, S., Popa, O., List, J. M., Geisler, H., Martin, W. F., \& Dagan, T. (2013). Reconstructing the lateral component of language history and genome evolution using network approaches. In H. Fangerau, H. Geisler, T. Halling, \& W. F. Martin (Eds.), Classification and evolution in biology, linguistics and the history of science (pp. 163-180). Stuttgart: Steiner.

Nuño de la Rosa, L., Etxeberria, A. (2012). Pattern and process in evo-devo: Descriptions and explanations. In H. de Regt et al (Eds.), EPSA Philosophy of Science, Amsterdam 2009, The European Philosophy of Science Association Proceeding 1 (pp. 263-274). doi:10.1007/978-94-007-2404-4_23.

Odling-Smee, F. J., Laland, K. N., \& Feldman, M. W. (2003). Niche construction: The neglected process in evolution. Princeton, $\mathrm{NJ}$ : Princeton University Press.

O'Neill, R. V., De Angelis, D., Waide, J., \& Allen, T. F. H. (1986). A hierarchical concept of ecosystems. Princeton, NJ: Princeton University Press.

Oparin, A. I. (1968). Genesis and evolutionary development of life. New York: Academic Press.
Oparin, A. I., \& Gladilin, K. L. (1980). Evolution of self-assembly of probionts. BioSystems, 12, 133-145.

Orgel, L. E. (1973). The origins of life: Molecules and natural selection. New York: Wiley.

Oyama, S., Griffiths, P. E., \& Gray, R. D. (2001). Cycles of contingency, developmental systems and evolution. Cambridge, MA: MIT Press.

Pattee, H. H. (1970). The problem of biological hierarchy. In C. H. Waddington (Ed.), Toward a theoretical biology ( $\mathrm{pp}$. 117-136). Edinburgh: Edinburgh University Press.

Pattee, H. H. (Ed.). (1973). Hierarchy theory: The challenge of complex systems. New York: Braziller.

Pearson, J. C., Lemons, D., \& McGinnis, W. (2005). Modulating Hox gene functions during animal body patterning. Nature Reviews Genetics, 6, 893-904.

Piaget, J. (1950). Introduction à l'épistémologie génétique (Vol. 3). Paris: Presses universitaires de France.

Pigliucci, M., \& Müller, G. B. (Eds.). (2010). Evolution: The extended synthesis. Cambridge, MA: MIT Press.

Pinxten, R. (1997). When the day breaks. Berlin: Peter Lang.

Popa, O., Hazkani-Covo, E., Landan, G., Martin, W., \& Dagan, T. (2011). Directed networks reveal genomic barriers and DNA repair bypasses to lateral gene transfer among prokaryotes. Genome Research, 21(4), 599-609.

Popper, K. (1957). The poverty of historicism. London: Routledge.

Prigogine, I. (1980). From being to becoming. New York: Freeman.

Prigogine, I. (1990). Time, dynamics and chaos: Integrating Poincare's 'non-integrable systems'. Center for Studies in Statistical Mechanics and Complex Systems at the University of TexasAustin, http://www.osti.gov/accomplishments/display_biblio. jsp?id $=$ ACC0300\&numPages $=27 \& \mathrm{fp}=\mathrm{N}$.

Prüfer, K., Racimo, F., Patterson, N., Jay, F., Sankararaman, S., Sawyer, S., et al. (2014). The complete genome sequence of a Neanderthal from the Altai mountains. Nature, 505(7481), 43-49.

Riedl, R. (1977). A systems-analytical approach to macroevolutionary phenomena. Quarterly Review of Biology, 52, 351-370.

Riedl, R. (1984). Biology of knowledge: The evolutionary basis of reason. New York: Wiley.

Rieppel, O., \& Grande, L. (1994). Summary and comments on systematic pattern and evolutionary process. In L. Grande, O. Rieppel (Eds.), Interpreting the hierarchy of nature (pp. 227-255). San Diego, CA: Academia Press.

Sagan, L. (1967). On the origin of mitosing cells. Journal of Theoretical Biology, 14(3), 255-274.

Salthe, S. (1985). Evolving hierarchical systems: Their structure and representation. New York: Columbia University Press.

Schlichting, C., \& Pigliucci, M. (1998). Phenotypic evolution: A reaction norm perspective. Sunderland: Sinauer Associates.

Simon, H. A. (1962). The architecture of complexity. Proceedings of the American Philosophical Society, 106, 467-482.

Simpson, G. G. (1944). Tempo and mode in evolution. New York: Columbia University Press.

Simpson, G. G. (1953). Life of the past: An introduction to paleontology. Connecticut, NH: Yale University Press.

Skinner, B. F. (1953). Science and human behavior. New York: Macmillan.

Skinner, B. F. (1984). The evolution of behavior. Journal of the Experimental Analysis of Behavior, 41, 217-221.

Smocovitis, V. B. (1996). Unifying biology: The evolutionary synthesis and evolutionary biology. Princeton, NJ: Princeton University Press.

Spencer, H. (1876). The principles of sociology (Vol. 2). New York: Appleton. 
Syvanen, M. (1985). Cross-species gene transfer; implications for a new theory of evolution. Journal of Theoretical Biology, 112(2), 333-343.

Szathmáry, E., \& Maynard Smith, J. (1995). The major evolutionary transitions. Nature, 374(6519), 227-232.

Thompson, D. W. (1917). On growth and form. Cambridge: Cambridge University Press.

Tinbergen, N. (1963). On aims and methods of ethology. Zeitschrift für Tierpsychologie, 20, 410-433.

Turing, A. M. (1952). The chemical basis of morphogenesis. Philosophical Transactions of the Royal Society of London, 237(641), 37-72.

Van Valen, L. A. (1976). Ecological species, multispecies, and oaks. Taxon, 25, 233-239.

Vernot, B., \& Akey, J. M. (2014). Resurrecting surviving Neanderthal lineages from modern human genomes. Science, 343(6174), $1017-1021$.

Vollmer, G. (1984). Mesocosm and objective knowledge: On problems solved by evolutionary epistemology. In F. Wuketits
(Ed.), Concepts and approaches in evolutionary epistemology (pp. 69-121). Dordrecht: D. Reidel Publishing Company.

Vrba, E. S. (1985). Environment and evolution: Alternative causes of the temporal distribution of evolutionary events. South Africa Journal of Science, 815, 229-236.

Watson, J., \& Crick, F. (1953). Molecular structure of nucleic acids. Nature, 171, 737-738.

West-Eberhard, M. J. (2003). Developmental plasticity and evolution. Oxford: Oxford University Press.

Williams, G. C. (1966). Adaptation and natural selection. Princeton, NJ: Princeton University Press.

Wimsatt, Z. (1980). Randomness and perceived-randomness in evolutionary biology. Synthese, 43(2), 287-329.

Woese, C. R. (1967). The genetic code. New York: Harper and Row.

Woese, C. R. (2004). A new biology for a new century. Microbiology and Molecular Biology Reviews, 68(2), 173-186.

Zilber-Rosenberg, I., \& Rosenberg, E. (2008). Role of microorganisms in the evolution of animals and plants: The hologenome theory of evolution. FEMS Microbiology Reviews, 32, 723-735. 